\title{
QUERATOPLASTIA LAMELAR POSTERIOR
}

\section{POSTERIOR LAMELLAR KERATOPLASTY}

\author{
VILLARRUBIA $A^{1}$
}

Desde que en 1998 Gerrit Melles publicara el primer caso exitoso de restauración de la transparencia corneal mediante el recambio de las capas posteriores de la córnea en un paciente con queratopatía bullosa (1), el tratamiento del edema corneal por disfunción endotelial mediante la queratoplastia lamelar posterior (PLK: Posterior Lamellar Keratoplasty) ha aumentado en frecuencia. La principal ventaja de la técnica descrita por Melles era que, mediante un abordaje posterior con una incisión escleral de $9 \mathrm{~mm}$, podía accederse a recambiar el endotelio, la membrana de Descemet (MD) y el estroma posterior mediante un disco donante con las mismas capas. Con esta incisión, se conseguía que el astigmatismo post-queratoplastia no fuera una rémora en el control postoperatorio; esta ventaja, unida a lo que, intuíamos, podía ser una recuperación funcional más rápida y un postoperatorio con menos complicaciones, hizo que cirujanos de medio mundo peregrináramos a Rotterdam para incorporar a nuestra práctica este procedimiento que se nos antojaba, cuando menos, prometedor. El propio Melles ideó una maniobra para reducir el tamaño de la incisión a 5 $\mathrm{mm}$ : tal era plegar el disco donante a la manera de un taco mexicano y así introducirlo en la cámara anterior del receptor para desplegarlo dentro.

Fue Mark Terry quien comenzó a publicar series realmente importantes de pacientes que habían sido tratados con la técnica que él llamó Queratoplastia Lamelar Endotelial Profunda (DLEK: Deep Lamellar Endothelial Keratoplasty) (2), basada en la PLK de Melles pero realizada con instrumental específico desarrollado por Terry. Durante varios años, Terry fue prácticamente el único autor que trabajó para demostrar que la PLK/DLEK era una técnica superior a la queratoplastia penetrante $(\mathrm{QP})$ en términos de astigmatismo postoperatorio y de recuperación funcional temprana. Terry hizo una especie de solitaria travesía del desierto y debemos reconocer su empeño en que la PLK/DLEK no cayera en el olvido.
En 2004, de nuevo Melles describió una maniobra quirúrgica que simplificó el procedimiento: extraer la MD de la córnea receptora para que el disco donante pueda quedar adherido a un lecho mucho más homogéneo. Esta maniobra, llamada descemetorrexis (3), simplificó el acto quirúrgico en su fase receptor y varios grupos en Estados Unidos (4) comenzaron a realizar una nueva técnica que denominaron DSEK (Descemet's Stripping Endothelial Keratoplasty: Queratoplastia Endotelial con pelado de la membrana de Descemet). Sin embargo, la disección manual del disco donante continuaba siendo un problema desde el punto de vista técnico. La obtención del disco donante mediante una queratotomía realizada con microqueratomo sobre una cámara anterior artificial hizo que la técnica fuese mucho más reproducible aún y que ambos lechos, donante y receptor, se unieran de una forma más homogénea (5). Esta técnica ha sido bautizada como DSAEK (Descemet's Stripping with Automated Endothelial Keratoplasty: Queratoplastia Endotelial Automática con pelado de la membrana de Descemet) y es la que actualmente realizamos todos los cirujanos de córnea que creemos en los beneficios del trasplante lamelar versus el penetrante.

Lógicamente, toda esta evolución técnica ha ido acompañada de la publicación de resultados. No hay duda de que en términos de inducción astigmática, tiempo para la recuperación funcional, estabilidad refractiva, y complicaciones postoperatorias, las técnicas de recambio de las capas posteriores de la córnea son superiores a la QP (2). Lo que los detractores de las técnicas lamelares invocan continuamente para contraponerlas a la QP es que la agudeza visual corregida de un ojo con una doble capa en la córnea nunca puede ser la misma que en una córnea virgen. A esta limitación se une, en el caso de la introducción de un disco donante plegado, la pérdida endotelial inherente al acto quirúrgi-

\footnotetext{
1 Licenciado en Medicina. Instituto de Oftalmología La Arruzafa. Córdoba. España.

E-mail: alvillarrubia@yahoo.com
} 
co. Los resultados publicados en DLEK y DSAEK reflejan una media de agudeza visual corregida (AVCC) de 20/40 (20/20 - 20/200) (2) y de 20/34 \pm 1,1 líneas (6) respectivamente. Deberíamos sin embargo preguntarnos si la ventaja de obtener en contados casos una AVCC de 20/20 al año de una QP no es sobrepasada por el hecho que supone tener a una mayoría de pacientes con una agudeza visual sin corregir al mes de 20/50 - 20/40 con una técnica quirúrgica que tiene una incidencia de complicaciones sensiblemente inferior. En cuanto a la segunda desventaja de la PLK respecto a la QP hay que hacer notar que en una documentada serie publicada por Terry en ojos con distrofia de Fuchs, la pérdida de células endoteliales después de DLEK/DSEK fue similar a la reportada en la literatura después de QP a los dos años (43\% en DLEK vs. $35 \%$ a $53 \%$ en QP) (7). Por último, una complicación del postoperatorio inmediato inherente a DSAEK como es la dislocación del disco receptor, ha dejado de ser una limitación importante debido a la descripción de maniobras quirúrgicas (4) que han disminuido la incidencia de este evento.

Muchos de nosotros nos hemos preguntado porqué esta técnica se está consolidando en Estados Unidos y en Europa continuamos sin incorporarla de una manera más frecuente en nuestro vademécum quirúrgico. Cuando se han realizado varios casos de DSAEK, uno puede darse cuenta de que los mejores resultados funcionales se obtienen en pacientes que no tienen alterado aún el estroma corneal, o sea, con edema corneal exclusivamente. Probablemente, en nuestro medio estamos más habituados a ofrecer la cirugía de recambio corneal a pacientes con ojo doloroso y, normalmente, con fibrosis en el estroma corneal: en estos ojos la técnica puede funcionar para eliminar las molestias del paciente, pero la experiencia comienza a enseñarnos que los resultados visuales son pobres. Si al hecho de precisar una cirugía precoz añadimos que la cada vez menor complejidad técnica de DSAEK permite realizarla asociada a facoemulsificación del cristalino y con anestesia tópica, deberíamos comenzar a plantearnos si el gold estándar en el tratamiento del edema corneal por disfunción endotelial debe ser la QP o si deberíamos establecerlo ya en la DSAEK. Es de esperar que, a medio plazo, veamos publicadas series amplias de pacientes tratados con DSAEK y podremos compararlas con los resultados de la QP en cuanto a pérdida de células endoteliales y supervivencia del injerto.
Probablemente, en poco tiempo, y mientras esperamos a un hipotético tratamiento definitivo para regenerar el endotelio corneal sin tener que recurrir a complejas técnicas quirúrgicas, será el láser de femtosegundo la tecnología empleada para preparar el lecho receptor y para conseguir un homogéneo disco donante (FS-DSEK); aunque, conociendo la historia, no debemos perder de vista lo que ocurra con una nueva técnica descrita por Gerrit Melles (8) y que consiste en el recambio de la MD con el endotelio corneal y sin estroma posterior (DMEK: Descemet's Membrane Endothelial Keratoplasty).

Gerrit Melles es un autor absolutamente innovador en la cirugía corneal y ello es reconocido en la mayoría de las publicaciones sobre alguna innovación técnica y/o de resultados con las técnicas ya existentes en cirugía lamelar corneal. Mark Terry ha sido la persona que con su esfuerzo ha conseguido generalizar el interés por continuar la evolución de dichas técnicas. A ambos autores debemos admiración y agradecimiento por ofrecernos su talento y su trabajo para la más pronta y segura recuperación de nuestros pacientes con un endotelio corneal dañado.

\section{BIBLIOGRAFÍA}

1. Melles GR, Lander F, Beekhuis WH, Remeijer L, Binder PS. Posterior lamellar keratoplasty for a case of pseudophakic bullous keratopathy. Am J Ophthalmol 1999; 127: 340-341.

2. Terry MA, Ousley PJ. Deep Lamellar endothelial keratoplasty visual acuity, astigmatism, and endothelial survival in a large prospective series. Ophthalmology 2005; 112: 1541-1548.

3. Melles GR, Wijdh RH, Nieuwendaal CP. A technique to excise the descemet membrane from a recipient cornea (descemetorhexis). Cornea 2004; 23: 286-288.

4. Price FW Jr, Price MO. Descemet's stripping with endothelial keratoplasty in 200 eyes: Early challenges and techniques to enhance donor adherence. J Cataract Refract Surg 2006; 32: 411-418.

5. Gorovoy MS. Descemet-stripping automated endothelial keratoplasty. Cornea 2006; 25: 886-889.

6. Covert DJ, Koening SB. New triple procedure: Descemet's stripping and automated endothelial keratoplasty combined with phacoemulsification and intraocular lens implantation. Ophthalmology 2007; 114: 1272-1277.

7. Terry MA, Wall JM, Hoar KL, Ousley PJ. A prospective study of endothelial cell loss during the 2 years after deep lamellar endothelial keratoplasty. Ophthalmology 2007; 114: 631-639.

8. Melles GR, Ong TS, Ververs B, van der Wees J. Descemet membrane endothelial keratoplasty (DMEK). Cornea 2006; 25: 987-990. 